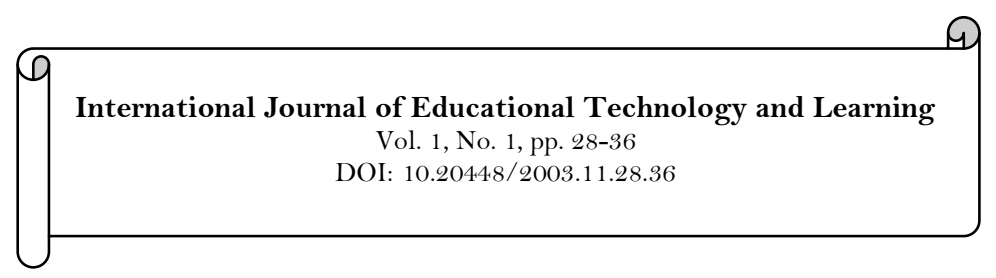

\title{
Learning Methodologies for Learners with Dyslexia
}

\author{
Sandro Sehic ${ }^{1}$ \\ ${ }^{1}$ MVCC Education Opportunity Center, 524 Elizabeth St., Utica, NY, USA.
}

\begin{tabular}{|c|c|}
\hline Abstract & \\
\hline \multirow[t]{2}{*}{$\begin{array}{l}\text { Dyslexia is a common reading disability that prevents many people } \\
\text { from learning to read and sometimes completely disrupts all } \\
\text { elements of the learning process if not addressed by educators. As a } \\
\text { disability, dyslexia, cannot be cured; however, with proper teaching } \\
\text { methods, it's possible to significantly minimize the effects to allow } \\
\text { students with dyslexia to successfully learn as well as those without } \\
\text { dyslexia. The purpose of this article is to provide information about } \\
\text { dyslexia and discuss some of the teaching methods educators can use } \\
\text { to help learners with dyslexia overcome reading barriers and become } \\
\text { successful learners. }\end{array}$} & $\begin{array}{l}\text { Keywords: } \\
\text { Dyslexia } \\
\text { Learning methodologies } \\
\text { Reading disability } \\
\text { Reading skills. } \\
\text { Licensed: } \\
\text { This work is licensed under a } \\
\text { Creative Commons Attribution } \\
\text { 4.O License. }\end{array}$ \\
\hline & $\begin{array}{l}\text { Publisher: } \\
\text { Scientific Publishing Institute }\end{array}$ \\
\hline
\end{tabular}

\section{Introduction}

The reading process can be described as the process of decoding written language. According to Penguin Dictionary of Psychology (2009) the reading process is "in simplest terms, the process by which information is extracted from written or printed language" (para. 1). Unlike the reading and the writing processes that are part of human development, educators and psychologists consider the reading process to be one of the most difficult tasks to accomplish, because it is not biological one. According to Sousa (2001) a leading researcher on the reading process,

The brain's ability to acquire spoken language with amazing speed and accuracy is the result of genetic hard-wiring and specialized cerebral areas that focus on this task. But there are no areas of the brain that specialize in reading. In fact, reading is probably the most difficult task we ask the young brain to undertake. Reading is a relatively new phenomenon in the development of humans. As far as we know, the genes have not incorporated reading into their coded structure, probably because reading —unlike spoken language— has not emerged over time as a survival skill. (p. 87)

If we accept the theory that the reading process is not naturally embodied in human genes and is not part of our natural development, we might assume that learning to read can be very easily disrupted, as can any other learning process by various learning disabilities.

The purpose of this paper is to explore one such reading disability, known as dyslexia, and the reading strategies that will help the learners with dyslexia to overcome this disability and learn to read. This research paper is based on a limited number of research materials and should not be generalized by the scientific community. It can serve only as a general overview of dyslexia and the reading strategies that can help minimize its effects.

\section{Definition of Dyslexia}

Dyslexia is a reading disability that deprives learners of the ability to read. It appears in many different forms and has many different causes. In addition, it affects learners throughout the world in different ways depending on their native alphabet. According to Sousa (2001), dyslexia is a learning disability that "results from a defect in the ability to process graphic symbols" (p. 95). In the Cambridge Handbook of Psychology (2007) dyslexia is described as "a developmental disorder in the acquisition of reading skills, in children of otherwise normal intelligence, which cannot be explained on the basis of educational depravation or sensory impairment" 
(para. 1). Learners diagnosed with dyslexia usually show various symptoms that are all affiliated with a lack of reading skills. Those symptoms include, but are not limited to:

Difficulty to recognize written words.

Difficulty rhyming or sequencing syllables.

Difficulty determining the meaning or main idea of a simple sentence.

Difficulty encoding words-spelling.

Poor sequencing or letters or numbers.

Delayed spoken language.

Difficulty separating the sounds in spoken words.

Difficulty in expressing thoughts verbally.

Confusion about right or left handedness.

Difficulty with handwriting.

Possible family history of dyslexia. Sousa (2001)

The nature of dyslexia and how it disturbs reading abilities is still unknown and is highly disputed. For some scientists, the main causes of these symptoms that prevent learners with dyslexia from learning to read may lei in the fact that they have a difficult time retrieving phonological information from their short-term and long-term memory. In this case, phonological information refers to phonemic awareness: "an understanding that speech is composed of a series of written sounds; a powerful predictor of children's later reading achievement" (Vacca et al., 2003). Educators believe that learners with dyslexia fail to store and retrieve this phonological information properly from both short- and long-term memories.

The most consistently reported phonological difficulties found in dyslexia are limitations of verbal short-term memory and problems with phonological awareness. Phonological awareness refers to the ability to reflect consciously on the sound structure of words in order to make judgments about their rhyming relationships (e.g., the odd one out of sun, gun, rub, fun), or about the phonemes they contain (e.g., 'bice' without the /b/ is ice). [Children with dyslexia $]^{1}$ also have difficulties with the retrieval of phonological information from long-term memory... The strength of the evidence pointing to the phonological deficits associated with dyslexia has led to the proposal that it should be defined as a core phonological deficits. Importantly, within the phonological deficit model of dyslexia, poor phonological is related to poor reading performance, irrespective of IQ (Dyslexia, 2005).

Scientists who support this theory define dyslexia as a learning disability that is a product of abnormalities in the nervous system.

Some findings, however, show that dyslexia may not be caused by readers' inability to retrieve information from their memories, but rather by visual impairments. That means that dyslexia in some cases is not a product of intellectual disabilities but visual ones. According to Sousa (2001) dyslexia is also a product of a visual impairment known as visual magnocellular deficit: "impairment in this system may cause letters on a page to bundle and overlap, or appear to move - common complaints from some [individuals with dyslexia ${ }^{2}$ ]" (p. 97). One potential reason that dyslexia may be classified as a visual disability that causes reading problems is the fact that some people with visual disabilities cannot see the differences between similar-looking letters. Sousa also points that "because [individuals with dyslexia ${ }^{3}$ ] often confuse $b$ and $d$, psychologists thought for many years that dyslexia was merely a vision problem” (p. 95).

In addition to intellectual and visual disabilities, dyslexia may appear as the result of brain injury. This type of "acquired dyslexia" is mostly common among adults. According to Brown (2011) an expert and researcher on learning disabilities, "in adults, dyslexia usually occurs after a brain injury or in the context of dementia. In children it usually occurs as a result of environmental influences after birth" (para. 4). Some groups of scientists, however, disagree that dyslexia is a product of intellectual and visual disabilities and believe the real cause and nature of dyslexia to be unknown. According to Friend and Bursuck (2002) "perhaps the best way to describe dyslexia at this point is to say that it is a term used to describe any serious reading disability" (p. 208). Whatever the origins of dyslexia, be the neurobiological or visual, the scientific community continues to recognize it as a reading disability that deprives learners from developing reading skills and learning to read.

\section{Different Types of Dyslexia}

Since the origins of dyslexia are still highly disputed, scientists tend to distinguish among several different types of dyslexia that deprive certain individuals from acquiring reading abilities. Dyslexia can appear as the product of brain injuries, intellectual disabilities, or visual disabilities. Some types of dyslexia can be easily "treated" by special teaching methods, while others may remain "untreated" and deprive an individual

of developing any reading abilities. The types of dyslexia caused by the brain injuries are much harder to overcome than those caused by visual disabilities.

\footnotetext{
' Expression "dyslexic children" was replaced with "children with dyslexia."

2 Term "dyslexics" was replaced with "individuals with dyslexia."

${ }^{3}$ Term "dyslexics" was replaced with "individuals with dyslexia."
} 
According to Perlstein (2011) "there are several types of dyslexia that can affect the child's ability to spell as well as read” (para. 4). Those types of dyslexia are recognized as: trauma dyslexia, primary dyslexia, and secondary or developmental dyslexia. Perlstein (2011) describes trauma dyslexia as the type of dyslexia that "usually occurs after some form of brain trauma or injury to the area of the brain that controls reading and writing. [And] it is rarely seen in today's school-age population” (Perlstein, 2011). Primary dyslexia, on the other hand, is not caused by brain injury but rather a brain abnormality. According to Perlstein (2011) "this type of dyslexia is a dysfunction of, rather than damage to, the left side of the brain (cerebral cortex) and does not change with the age" (para. 6). The third type of dyslexia, known as secondary or developmental dyslexia, "is felt to be caused by hormonal development during the early stages of fetal development. Developmental dyslexia diminishes as the child matures" Perlstein (2011).

Another classification of the different types of dyslexia is provided by Brown, who identified two additional types of dyslexia caused by visual and hearing disabilities. These are visual dyslexia and phonological (auditory) dyslexia. According to Perlstein (2011) visual dyslexia "is the result of immature development of not only the eyes, but the whole process that gets the information from the eyes to the brain" (para. 6). Phonological, or auditory dyslexia, "involves difficulty with sounds of letters or groups of letters. When this form of dyslexia is present, the sounds are perceived as jumbled or not heard correctly" (para. 8).

Regardless of what type of dyslexia a learner may have, it is very important to know that dyslexia may be accompanied by other learning disabilities. Those disabilities include, but are not limited to: attention deficit hyper-activity disorder (ADHD), attention deficit disorder (ADD), dyspraxia (the inability to perform minor and gross movements), dysgraphia (the inability to handle a pencil), dyscalculia (the inability to recognize numbers and solve math problems), Asperger's syndrome (a less-severe type of autism), and other similar disabilities that directly affect the learning abilities. Among learners with dyslexia, an inability to read may also be affected by the inability to write and hear. Psychologists and educators must take this possibility into consideration when testing learners for dyslexia. In addition, educator will have to select appropriate teaching methods to help learners to overcome the effects of dyslexia that impede their reading process.

\section{4. 'Teachers' Awareness of Dyslexia}

In order to help their students overcome the learning barriers caused by dyslexia, teachers will have to understand and become familiar with the main characteristics of this reading disability and how they disturb the reading process. Research studies suggest that many teachers and school officials are unfamiliar with dyslexia and its effects on the learning process. This lack of understanding among educators and the school officials may seriously deprive students with dyslexia to learn to read.

When studying beliefs, Wadlington and Wadlington (2005) found that numerous groups of educators (i.e., elementary regular education teachers, secondary regular education teachers, special educators, school counselors, administrators, university faculty) have significant misconceptions about dyslexia, often feel inadequate to work with students with dyslexia, and sincerely want to know more about how to provide effective instruction to students with dyslexia. Wadlington, Elliot, and Kirylo

(2008)

One possible reason for teachers' lack of knowledge about dyslexia may be because the special-education programs for teachers tend to be fairly general. That means that special-education teachers receive general education and training about dyslexia that

do not provide them with in-depth knowledge about this reading disability. Wadlington et al. (2008) state "that special education teacher education programs are too generic and that special education teachers should earn reading certifications to prepare them to work with student with dyslexia” (p. 265).

We may never expect all educators to learn everything about dyslexia and other learning disabilities, nor can we build schools that will provide specialized instruction only for learners with dyslexia. School officials can, however, ensure that all special education teachers, as well as general teachers, become aware of the main features of dyslexia and how this reading disability affects the learners.

When writing lesson plans and selecting teaching methods for learners with dyslexia, educators should understand that dyslexia does not impact learners' IQ. According to Dore (2008) an average learner with dyslexia "often has average or above-average IQ, but doesn't do as well on school tests as they should" (p. 19). Regardless of their learning disabilities, learners with dyslexia usually arrive at school with high expectations and motivation to learn but they very easily loose their will to learn once

they fail to read in the same way as their peers without dyslexia. According to Wadlington et al. (2008), "because persons with dyslexia usually have many strengths, teachers are often surprised when a student with dyslexia has extreme difficulty in reading" (p. 264).

In addition to their reading disability, learners with dyslexia may be very easily be affected by the other learning disabilities that normally accompany dyslexia. Dore (2008) reports that learners with dyslexia may also be affected by attention deficit hyperactivity disorder (ADHD), or Asperger's syndrome. Without the ability to progress through the learning process, learners with dyslexia may easily abort the learning process altogether. Wadlington et al. (2008) state that "when school experiences are negative, many students develop 
social and emotional problems such as low self-esteem, frustration, helplessness, stigma, and depression” (p. 265).

Teachers should be aware, however, of the fact that dyslexia is difficult to be diagnose. Usually, all new learners struggle with reading at first, regardless of whether they have dyslexia. If a learner becomes frustrated with reading, it will not automatically mean that he or she may suffers from dyslexia. Perlstein (2011) suggests that "classroom teachers may not be able to determine if a child has a dyslexia. They may detect early signs that suggest further assessment by a psychologist or other health professional in order to actually diagnose the disorder" (para. 1). Even if it is not the classroom teachers' job to diagnose dyslexia, their job is certainly to recognize the early symptoms of dyslexia. These early signs and symptoms should never be confused with the main symptoms of dyslexia. Perlstein (2011) suggests that if the early symptoms of dyslexia do not disappear by the age of 8 , it is a good indication that the learner may have dyslexia and need more detailed testing.

Letter and number reversals are the most common warning signs. Such reversals are fairly common up to the age of 7 or 8 and usually diminish by that time. If they do not, it may be appropriate to test for dyslexia or other learning problems. Difficulty copying from the board or a book can also suggest problems. There may be a general disorganization of written work. A child may not be able to remember content, even if it involves a favorite video or storybook (Perlstein, 2011)

Once the symptoms of dyslexia are recognized and the learner is diagnosed, however, teachers must take a different approach with their instructions. In the early grades, when working with early readers, teachers usually focus on helping their students learn to read and detecting early symptoms of reading disabilities. In higher grades, when teaching older students, teachers will encounter more students who are officially diagnosed with dyslexia. A diagnosis of dyslexia will only acknowledge that a particular learner has a reading disability, but unfortunately it will not provide information on the severity of their dyslexia. The scientific community does not recognize the degree to which dyslexia affects the learning process. It is up to teachers to determine the severity of dyslexia and to choose appropriate teaching methods to help learners with dyslexia to overcome their reading disability. Teachers should be aware that, although learners with dyslexia do not have low IQs, they may exhibit frustration with reading, due to their inability to read properly. In addition since the teachers are the only school professionals that will teach reading classes and will be most familiar with students' knowledge and learning skills, they should understand the early symptoms of dyslexia so that it can be diagnosed at the early stages.

\section{Reading Strategies for Learners with Dyslexia}

In order to help learners with dyslexia learn to read, teachers must use different teaching and learning strategies, especially when working with early learners and learners with basic reading skills. That means that younger learners with dyslexia who do not possess any reading skills will need a different approach to learning than their older learning partners who possess basic reading skills.

At the beginning of the learning process, teachers will have to use teaching strategies that help students to recognize letters and words. Later, as students progress through the learning process, teachers should incorporate teaching methods that help students learn to comprehend the reading material. In the later grades, once students already possess basic reading skills, teachers will must help students become familiar with the learning strategies that will help them maintain their reading skills, manage their learning time, and continue to improve their reading skills.

As previously stated, the individual learning plans (IEP) of students with dyslexia usually do not indicate whether their reading disabilities are minor, mild, or severe. When designing their teaching strategies, teachers must take this important factor into consideration. When learning to read, students with minor types of dyslexia will not need to use the learning strategies that normally help students with more severe types. Using proper teaching and learning methods will help both students and teachers achieve their desired academic objectives.

In the next pages, I present several learning strategies that I and my colleagues have used for the past three years to help learners with dyslexia learn to read and overcome this reading disability. The most useful characteristic of these learning and teaching methods is the fact that they can be easily modified to match students' learning abilities. In addition, the following learning and teaching strategies do not have to be supported by technology or special learning materials, making them practical for every learning environment.

\subsection{Basic Alphabet}

Teaching the basic alphabet is the first step in reading instruction. Learners with dyslexia, however, may find numerous similarities, rather than differences, among the letters. For example, students may very easily confuse the letters that look similar, such as $b, a$ and $d$, or $m$ and $n$.

In this teaching/learning method, teachers will first introduce capital letters by ensuring that similar letters of the alphabet are never placed next to each other. In addition, the names of the letters will have to be avoided and each letter indicated by a short sound in order for learners to avoid confusion. Teachers will write letters on the board or present them to students through cards or textbooks. Each letter should be indicated 
by one simple sound and not by the item whose name begins with that letter. In English language phonology, letters tend to produce different sounds throughout the language, so when learning the basic alphabet, learners with dyslexia should only learn one simple sound that represents that letter. The objective of this teaching/learning method is to teach students to recognize the letters of the alphabet so that they can proceed to the reading practices.

\subsection{Continuous and Stop Sounds}

This teaching/learning method will help students recognize different sounds in the words. Continuous sounds are those sounds that readers can pronounce and hold on to for a certain time. Unlike continuous sounds, stop sounds can be repeated only by one sound and cannot be held for a long time. For example, some letters that produce continuous sounds are: $o, a, e, s, r$, and $z$. These sounds can be found in words like oven $=$ oooooooven, apple=aaaaaaple, etc.

Stop sounds, on the other hand, can only be repeated by numerous sounds. Letters as $k, l$, $p$, and $t$ cannot be repeated in the same way as continuous sounds. When reading words that include stop sounds, students must emphasize those sounds in order to become familiar with the letter/sound relationship. For example, words like house begin with a stop sound that can be repeated: $h-, h-, h-, h-, h-, h o u s e$.

Teachers should begin this teaching method by using simple words that consist of three or four letters that are not similar in shape in order to help students avoid confusion. The first practice words that can be used in this teaching/learning strategy are: mop, set, run, fun, and pat. As the learners progress through the reading process, teachers will add more words that consist of more letters. The objective of this teaching/learning method is to teach learners that words consist of certain sounds that create meaning only when they are properly connected together. We start instruction with the short words that consist of dissimilar letters and then progress towards more complex words and, later, sentences.

\subsection{Sequence of Combined Sounds}

Sousa (2001) mentions this teaching strategy for learners with dyslexia who usually have a difficult time connecting vowels and consonants when they stand next to each other in a word. This is probably one of the most difficult reading barriers that learners with dyslexia must overcome. This disability is more common among the learners with severe dyslexia. It is important to know that not all learners with dyslexia will fail to recognize combination of vowels and consonants. Teachers must determine during the reading activities whether their students have a difficult time recognizing parts of the word where a vowel stands next to a consonant.

Sousa (2001) presents a three-step exercise that will help learners with dyslexia to overcome this particular barrier. According to Sousa, "when introducing the combined sounds, a consonant-vowel pattern should come first, then a vowel-consonant pattern, and finally, the consonant-vowel-consonant patter. For example: first tie, next add, and then bed' (p. 101).

Once teachers determine that students can recognize letters and understand that words consist of different letters that produce different sounds, they can start helping their students to read the whole word. This teaching method can work with all learners with dyslexia, regardless of their reading abilities. Students with severe dyslexia will learn to connect vowels and consonants properly, and students with mild dyslexia will learn to improve their reading fluency.

The objective of this teaching/learning strategy is to help student read the whole word so that they can progress towards more complex reading tasks. Teachers are free to choose any words that match the proper sequence. For example

a. Consonant-vowel pattern:

-mind, pat, feet, tie, car, window, room, house.

b. Vowel-consonant pattern:

-add, apple, empire, antenna.

c. Consonant-vowel-consonant pattern:

-mad, pan, seat, fleet.

Once the learners become able to properly connect vowels and consonants, then the teachers may start using regular words regardless of their letter sequence. The objective of this teaching method is to help students to properly connect vowels and consonants and to slowly start progressing towards more advanced reading tasks.

\subsection{Puzzle Words}

Using puzzle words, also known as domino words, is an advanced teaching strategies for learners with dyslexia. The objective of this strategy is to teach students the sequence of words in a sentence. This teaching method can be used only once students have learned to recognize all the letters of the alphabet and their sounds. During this activity, teachers should provide students with word-cards (one word per card) that will be put in proper sequence so that they represent a sentence with a particular meaning. 
This teaching activity is divided into two parts. During the first part, teachers will provide students with sheets that include one or more sentences and the word-cards that include the same words from the given sentences. During this part of the learning activity, students will place a word-card under the same word in the sentence.

\section{Sentence: \\ I

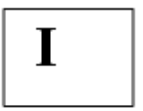 \\ can

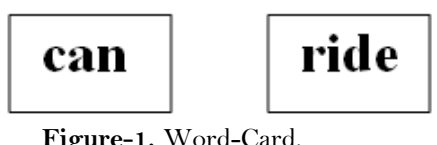 \\ a

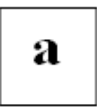 \\ bike. \\ Word-card: \\ Figure-1. Word-Card.}

In the second part of this teaching strategy, teachers will read the sentence to students, and their task will be to assemble the sentence using the word-cards. Teachers should move to this part of teaching/learning only once they notice that their students are comfortable with "assembling" the sentences and reading them correctly.

\subsection{Word/Sentence Recognition}

Word/sentence recognition is a teaching strategy that can be used with all learners with dyslexia, especially those students with severe dyslexia who cannot recognize certain letters of the alphabet. If students fail to learn to recognize certain letters of the alphabet, they will fail to become familiar with phonological awareness, but it does not mean that they cannot learn to read. Bird, Cleave, and McConnell (2000) suggest that "not all children depend on phonological awareness in order to learn to read" (p. 319). Bird, Cleave and McConnell conducted their research among children with Down syndrome concluded that children may learn to read without phonological awareness by focusing directly on word recognition.

In order to help students learn the meaning of the words and the sentences, teachers will incorporate several learning steps in this activity. Each step will make learners with dyslexia more comfortable with the text and help them improve their reading skills.

First step: Teachers will write a specific word or even a whole sentence on the board and read it aloud with their students.

Second step: Once students become familiar with the words and the sentences being studied during the learning activity, they can practice matching the words with their meanings. For example, teachers may provide students with the pictures of certain items and the word-cards to be matched with the words that represent their meaning.

This learning activity can also be performed on the computer. Numerous software programs will allow students to practice their reading skills by indicating certain words

when they hear the sound of that word. The students will learn to recognize the meaning of the words, not by identifying all sounds of the letters, but rather by the shape of certain letters.

\section{Learning Strategies for Learners with Dyslexia in Postsecondary Education}

Most research projects on dyslexia have been conducted among learners from elementary, middle, and high schools. Few research projects of this kind, however, have been conducted among learners with dyslexia who attend postsecondary education. Even though learners with dyslexia in postsecondary education differ significantly from students who attend secondary and elementary school, they must still deal with reading disabilities as much as younger learners who are learning the first letters of the alphabet.

Unlike younger learners with dyslexia, postsecondary learners with dyslexia can already read, but not as efficiently as learners without dyslexia. In their research on the reading abilities of postsecondary learners with dyslexia, Kirby, Silvestri, Allingham, Parrila, and La (2008) determined that postsecondary learners with dyslexia can achieve their desired academic goals even if their learning process is significantly impeded. The results of this research are a good indication that special teaching methods are necessary for postsecondary learners with dyslexia as much as for the younger learners. According to Kirby et al. (2008):

Although the learning strategies and study approaches or typically achieving students have been studied extensively (Biggs, 1987; Entwistle \& Ramsden, 1983). Little is known about the methods that postsecondary students with dyslexia employ to cope with their academic responsibilities (p. 86).

Moreover, learners with dyslexia, as with any other learners with learning disabilities, are less likely to report that disability to their professors or educational officials. According to the findings of Kirby et al. (2008),

Many students, however, do not disclose their [learning disabilities] LD upon admission to postsecondary institutions. Based on this lack of disclosure, Horn and Berktold (1999) estimated the proportion of undergraduate students with LD in the United States to be $1.61 \%$ (p. 85).

Because of these findings, postsecondary institutions and their officials must be prepared to offer assistance to learners with dyslexia and help them achieve their academic goals. Teaching/learning methods 
that could help postsecondary learners with dyslexia overcome reading barriers differ significantly from the early teaching methods. Postsecondary learners with dyslexia already know to read and can comprehend reading material, unlike early learners with dyslexia. When teaching postsecondary learners with dyslexia, educators must rely on teaching/learning strategies that help students take control over their learning process. That means that learners with dyslexia must learn to control their reading time, identify the main idea in the text, properly classify newly learned information, and understand test taking skills fully. These methods were identified in the Learning and Study Strategies Inventory (LASSI). According to Kirby et al. (2008), "four LASSI scales measure the self-regulation component of strategic learning: Concentration, Time Management, Self-Testing, and Study Aids” (p. 86).

\subsection{Focal Attention}

Comprehending the text and extracting the main ideas are the main objectives of any reading activity. Postsecondary learners with dyslexia will have to understand the meaning of the whole text and the reading assignment in order to learn new information and complete the written assignments. In order to understand the reading materials, they must focus on the reading material and avoid distraction from the environment, which requires them to develop cognitive flexibility. This is "a measure of the ability to ignore distractions to focus on relevant stimuli” (Jonassen \& Grabowski, 1993). A flexible learner "tends to concentrate more completely on the task at hand."

In order to help learners with dyslexia at postsecondary educational institutions develop cognitive flexibility, educators and school officials must make students aware of the learning process and the ways it can be disturbed by outside forces. Educators employed at postsecondary institutions cannot control learners' cognitive flexibility or fully prevent distraction from the environment: this is something learners will have to learn to do by themselves. Educators' duties are to explain the benefits of and methods for avoiding distraction. For example, learners can make their own lists of the things or actions that distract them and request special adjustments to facilitate their learning process. As well, learners may request more time for their reading assignments so they can read the text two or more times and fully understand the main idea.

Developing questioning strategies to provide learners with more information is another technique that might help learners to fully concentrate and understand the main idea of a text. Educators may provide their learners with the questionnaires they will have to complete along with their reading assignment. In that way, learners will use questions to extract the answers from the main text. These questions and answers will provide learners with the understanding of the main idea and help them avoid distraction to some extent. Cognitive flexibility can vary from learner to learner. Some will avoid distraction more easily than others. The learners should find their own ways of avoiding distraction from the environment and seek their teacher's assistance when necessary. Distractions may never be fully avoided, but their effects can be minimized so that they do not completely disrupt the learning process.

\subsection{Time Management}

Learning assignments have limits during which learners are expected to complete them. All learners with dyslexia may need more time in order to complete their assignments, especially reading assignments. The time limits may put them at a serious disadvantage if they do not learn to manage their time properly. Timemanagement skills are equally as important for learners with a learning disability as for those without. These skills help learners to allocate their learning time properly and complete the assignments on time.

The first step in helping learners with dyslexia manage their time is to help them organize study schedules with which to manage their learning assignments. Learning schedules should be organized into long-term and short-term schedules. Long-term schedules should be organized to show the deadlines of all assignments to be completed during the semester. Learners will use long-term schedules to carefully monitor assignment due dates in order to complete them on time, as well as to plan their study-time in advance. The long-term schedules will help learners organize their learning time and determine what assignments will have to be completed on specific days or at specific times of the day.

Once the learners have an overview of their long-term schedule, they can plan their short-term schedule, which will help them complete one given assignment at a time. The purpose of the short-term schedules is to help learners to allocate their time in order to complete each part of the assignment properly. Learners will have to know how much time should be used for writing activities, reading assignments, proofreading, and final submission of assignments. Postsecondary educational institutions offer numerous courses and seminars that provide learners with learning methods and help them manage their learning time. By attending those courses, learners will take best advantage of their learning time to accomplish their assignments.

\subsection{Self-Testing}

The purpose of self-testing techniques is to help learners test their own knowledge. Learners with dyslexia will have work constantly to improve their reading skills, even beyond secondary school. During their postsecondary education, they will encounter advanced reading materials and the assignments, which, will expose them to new words and longer texts. In order to better understand the meaning of these new 
reading materials, they must learn new words and constantly strive to improve their reading and writing skills. Self-testing is necessary in this process in order to help learners evaluate the progress of their learning.

Learners with dyslexia can use numerous methods to test their own knowledge. Some of the self-testing methods include:

1. Recording and listening your own reading activity

2. Checking knowledge of the new words by identifying their meanings, and their own ability to read and write those words.

When listening to the recordings of their own reading, learners with dyslexia will test their reading fluency and identify their reading strengths and weaknesses. The self-testing techniques will help the learners to learn what they need to improve in order to overcome their learning barriers completely. In addition, in order to better understand the meaning of the new words and expend their vocabulary, the learners can constantly test their knowledge of the new words by identifying the meaning of the new words and testing their writing and reading skills by using the new words. Self-testing will provide learners with information about their own progress, not only in reading skills but also in writing and language skills.

\subsection{Study Aids}

Study aids compromise everything that can help learners improve their reading skills and comprehend the reading material. Study aids can be live individuals, such as teachers, tutors, or study-buddies, as well as technological devices like computers, listening and recording devices, dictionaries, and electronic tablets, among others. Study aids can be especially useful for learners with severe dyslexia who cannot read at all. In this case, instead of reading the new assignments, learners will listen to them using devices that transfer text into sound. Technological devices will also help learners with dyslexia to interpret the meaning of new words, check the spelling of the written assignments, properly sound out new words, and proofread their whole assignment. Talking about the benefits of technological study aids in the twenty-first century can be a neverending story because modern technology may partially replace humans in the learning process.

On the other hand, teachers, tutors, and study-buddies are other sources of study aid. Learners with dyslexia who attend postsecondary educational institutions will have to extract teaching and learning methods from their teachers and tutors that will help them to become an independent learners. The main objective of every postsecondary learner with dyslexia is to become independent learner who will know to apply and use various learning strategies, manage his or her own learning time, and find the necessary information on their own.

\section{Conclusion}

Dyslexia is a complex reading disability that can be caused by neurobiological disorders as well as accidents that deprive individuals of the ability to acquire reading abilities. Dyslexia affects learners in different ways and to different degrees. Some individuals with dyslexia will have to cope with only mild cases of dyslexia and have reading disabilities go unnoticed, while other individuals with severe dyslexia may never be able to learn to read.

Scientific progress has revealed many facts about dyslexia and the information to the benefit of educators and learners. Access to this information has also helped many educators and scientists to develop teaching/learning strategies that help learners with dyslexia overcome their learning disabilities. What educators and learners with dyslexia must understand is that dyslexia cannot be cured or eliminated by medications or therapies. The effects of dyslexia can, however, be overcome by proper teaching and learning strategies that will minimize reading barriers and allow learners to achieve their academic goals.

Numerous teaching and learning strategies can help learners with dyslexia to succeed in their studies. These strategies, however, must be carefully selected by teachers or psychologists and used appropriately time in order to be successful. Younger learners with dyslexia will need more assistance from their teachers than will older learners with dyslexia who possess reading abilities. At the early stages of learning, educators will need to ensure that their learners learn to recognize the letters of the alphabet and acquire reading abilities that will help them to comprehend the reading material. As learners progress through their learning, educators must ensure that learners learn to acquire learning strategies that will help them to become independent learners and to take full control over their reading abilities.

Dyslexia neither affects learners' IQ nor causes any intellectual disability. Dyslexia is not a learning disability that cannot be controlled by learners and their

educators if the proper learning and teaching methods are used. With proper teaching and learning methods, however, along with support from educators and parents, all learners with dyslexia will be able not only to control their reading disability but also to complete postsecondary education.

\section{References}

Biggs, J. B. (1987). Student approaches to learning and studying. Melbourne, Australia: Australian Council for Educational Research. 
Bird, E. K., Cleave, P. L., \& McConnell, L. (2000). Reading and phonological awareness in children with down syndrome: A longitudinal study. American Journal of Speech-Language Pathology, 9(4), 319-330.

Brown, E. (2011). Understanding learning disabilities: IEP advocacy for special education. Retrieved from: http://www.understadning-learning-disabilities.com/index.html.

Dore, W. (2008). Dyslexia and ADHD-The miracle cure. London, England: John Blake Publishing Ltd.

Dyslexia. (2005). In Cambridge Encyclopedia of Child Development. Retrieved from: http://www.credoreference.com/entry/cupchilddev/dyslexia.

Entwistle, N. J., \& Ramsden, P. (1983). Understanding student learning. Croom Helm: London.

Friend, M., \& Bursuck, W. D. (2002). Including students with special needs: A practical guide for classroom teachers. Boston: MA: Allyn \& Bacon.

Horn, L. J., \& Berktold, J. (1999). Students with disabilities in postsecondary education: A profile of preparation, participation, and outcomes (Report No. NCES 1999- 187), . Washington, DC: Department of Education, National Center for Education Statistics.

Jonassen, D. H., \& Grabowski, B. L. (1993). Handbook of individual differences, learning E instruction. Hillsdale, NJ: Lawrence Erlbaum Associates, Inc.

Kirby, J. R., Silvestri, R., Allingham, B. H., Parrila, R., \& La, F. C. B. (2008). Learning strategies and study approaches of postsecondary students with dyslexia. Journal of Learning Disabilities, 41(1), 85-96.

Perlstein, D. (2011). What is dyslexia. Medicine Net.com. Retrieved from: http://www.medicinenet.com/dyslexia/article.htm.

Sousa, D. A. (2001). How the special needs brain learns. Thousand Oaks, CA: Corwin Press, Inc.

Vacca, J. L., Vacca, R. T., Gove, M. K., Burkey, L., Lenhart, L. A., \& McKeon, C. (2003). Reading and learning to read (5th ed.). Boston, MA: Allyn and Bacon.

Wadlington, E., Elliot, C., \& Kirylo, J. (2008). The dyslexia simulation: Impact and implications. Literacy Research and Instruction, 47(4), 264-272.

Wadlington, E., \& Wadlington, P. (2005). What do educators believe about dyslexia. Reading Improvement, 42(1), 16-33. 